\title{
PATTERN OF REFRACTIVE ERROR IN PRIMARY SCHOOL CHILDREN IN RUPANDEHI DISTRICT, NEPAL
}

\author{
Salma K.C. Rai ${ }^{1}$, Hari Bahadur Thapa ${ }^{2}$, Nanda Gurung ${ }^{3}$, Arjun Malla Bhari ${ }^{1}$, Manoj K Sharma ${ }^{1}$
}

\section{ABSTRACT}

INTRODUCTION: Refractive error remains one of the primary causes of visual impairment in children worldwide. This study describes pattern of refractive errors among primary school students in Rupandehi district, Nepal.

MATERIALAND METHODS: Records of 128 children with refractive error aged 5-15 years from both urban and rural areas in Nepal between January and March 2011 were examined for patterns in the distribution of refractive errors. SPSS statistical software was used to perform analysis.

RESULTS: The commonest type of refractive errors among the children was astigmatism (47\%) followed by myopia (26\%) and hyperopia (19\%). Children in the age group 11-15 years had higher number of eyes with refractive error as compared to their younger counterparts 5 years /or below 5 years (49\% vs. 9\%). $71 \%$ students were from schools located in rural areas. Among the children with refractive errors, only $44.5 \%$ students were wearing glasses. $57 \%$ of the students studying in private schools were wearing glasses but only $26.9 \%$ students from the government school were wearing glasses.

CONCLUSION: A wide variation in the distribution of refractive errors between the geographic locations, gender basis, types of schools as well as between the different ethnic groups was observed.

KEYWORDS: Refractive errors; Astigmatism; Visual impairment

1. Associate Professor,Lumbini Eye Institute, Bhairahawa, Nepal

2. Optometrist, Lumbini Eye Institute, Bhairahawa, Nepal

3. Consultant, Lumbini Eye Institute, Bhairahawa, Nepal

For Correspondence

Dr. Salma K.C. Rai, MD

Associate Professor,

Lumbini Eye Institute, Bhairahawa, Nepal

E-mail:drsalmakcrai@gmail.com 


\section{INTRODUCTION}

Refractive error remains one of the main causes of visual impairment in children worldwide. ${ }^{1-3}$ Prevalence of visual impairment in children, is defined as uncorrected vision equal to or worse than $20 / 40$, and it varies from as low as $2.72 \%$ in South Africa ${ }^{4}$ to as high as $15.8 \%$ in Chile. ${ }^{3}$ To address the problem of blindness in children, the World Health Organisation (WHO) recently launched a global initiative, VISION 2020-The Right to Sight, to eliminate avoidable blindness among children. ${ }^{5}$ Myopia is the most common refractive error in children. High myopia is associated with potentially blinding conditions such as retinal tear, retinal detachment, macular degeneration, cataract and glaucoma.Therefore, understanding the prevalence and underlying aetiological factors is important to reduce the prevalence of refractive errors.

Refractive error, particularly myopia, is a major issue in Asian countries. ${ }^{6,11}$ Furthermore, the prevalence of myopia has also increased among young Asian adult populations, as reported in a longitudinal 13 years study on students aged between 3 and 17 years by Hiroomi Matsumura et al. ${ }^{12}$

The progression of myopia was also noted to be more prevalent in older children, and was much higher than those reported in Western countries. In Taiwan, 2 studies involving school children aged 6 to 18 years showed a prevalence of more than $80 \%$ by the age of $18 .{ }^{13}$ Another study in a Japanese student population showed an overall prevalence of approximately $50 \%{ }^{14}$ A study in Hong Kong showed that myopia was not only at its highest prevalence as compared to other countries, but myopia has also occurred in younger age groups. ${ }^{9}$

Very few studies of the prevalence and distribution of refractive errors (myopia, hyperopia and astigmatism) among children in the western part of Nepal have been conducted. This study would provide informative figures better for planning in the national health program, and provide useful data on refractive error among primary school children, specifically in Lumbini Zone. This study is in line with the WHO campaign of Vision 2020, where children have the right to good sight.

\section{MATERIAL AND METHODS}

This study was carried out from January to March 2011, among primary school children in Rupandehi district, Nepal. Fifteen schools were randomly selected from the 148 registered primary schools of Rupandehi district. Inclusion criteria for this study encompassed all randomly selected primary school children from grade 1 to grade 5 in the district of Rupandehi. Consent was given by parents or guardians. Exclusion criteria included students who were already on ophthalmology follow-up for known ocular conditions, were absent from school on the examination day, refused visual acuity assessment or eye examination, and were inconsistent in visual acuity assessment after 3 attempts.

Visual acuity assessments and refraction (dry and cycloplegic) were performed by 2 trained optometrists. Visual acuity was taken using an alphabetical or tumbling E logMAR chart. Students who were unable to recognise alphabets were assessed using Tumbling E logMAR charts, while the remaining students were assessed using alphabetical logMAR chart.

Visual acuity assessments (presenting, uncorrected and bestcorrected) were done at 3 metres. A pinhole test was carried out if the visual acuity was equal to or worse than $6 / 12$. Students who were suspected of having refractive errors, using a referral criterion of uncorrected visual acuity equal to or worse than 20/40 (or an equivalent $\log$ MAR value of 0.3 ), were sent for further evaluation using retinoscopy techniques. Cycloplegic refraction was done using $1 \%$ Cyclopentolate and $1 \%$ Tropicamide eye drops applied in a C-T-C pattern, with five minutes between applications (CTC protocol). Cycloplegia was considered complete if the pupils were dilated more than $6 \mathrm{~mm}$. Refraction was performed using a streak retinoscope in a semidark room at a distance of $50 \mathrm{~cm}$. Refractive errors were classified according to the definitions given by Rainaldo D et al 2006. Data entry and analysis were implemented by utilizing SPSS version 12 . P value of less than .05 was considered as statistically significant.

\section{RESULTS}

Out of the total 5428 students screened from fifteen primary schools of Rupandehi district, 128 (2.36\%) had refractive error. The mean age was $10.3 \pm 2.9$ years with range 5 to 15 years. $49.2 \%$ of the children were in age group $11-15$ years, $41.4 \%$ in age group $6-10$ years and only $9.4 \%$ were in the age group 1-5 years. Maximum number of the students (39.8\%) were studying in grade five and minimum in grade one and two (8.6\% in each grade). $54.7 \%$ of the participants were boys and $45.3 \%$ were girls. Although the number of boys is greater than number of girls, statistically there was not significant difference (NPar test, $\mathrm{p}=0.331)$.

Most of the patients were with visual acuity in the range of $6 / 6$ 
to $6 / 18$. Visual acuity was $6 / 6$ to $6 / 18$ in 183 eyes without correction while 205 eyes of 128 students after spectacle wear. (Figure 1)

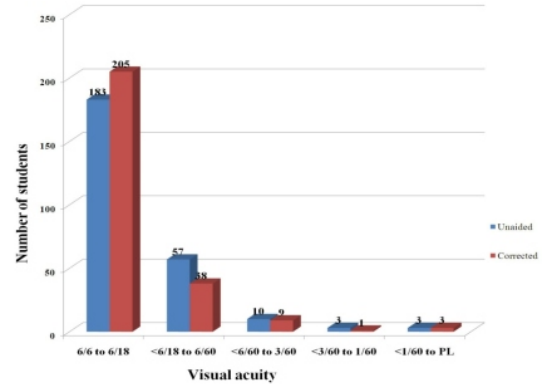

Figure 1. Visual acuity of the 256 eyes before and after correction.

As shown in table 1, 71.1\% (91) of the students were from schools located in rural area. Almost half of the students $(49.2 \%)$ were in the age group 11 to 15 years and minimum number of students $(9.4 \%)$ was in the age group 1 to 5 years. $40.6 \%$ (52) students were from government schools and remaining $59.4 \%$ (76) of the total patients were from private schools. (Table 2)

Table 1. Age and sex distribution in different location of the students.

\begin{tabular}{|c|c|c|c|c|c|}
\hline \multirow{2}{*}{ Location of the patients } & \multirow{2}{*}{ Sex } & \multicolumn{3}{|c|}{ Age group of patients in years } & \multirow{2}{*}{ Total } \\
\hline & & $1-5$ & $6-10$ & $11-15$ & \\
\hline \multirow{3}{*}{ Rural } & Male & 4 & 22 & 21 & 47 \\
\hline & Female & 4 & 17 & 23 & 44 \\
\hline & Total & 8 & 39 & 44 & 91 \\
\hline \multirow{3}{*}{ Urban } & Male & 1 & 10 & 12 & 23 \\
\hline & Female & 3 & 4 & 7 & 14 \\
\hline & Total & 4 & 14 & 19 & 37 \\
\hline
\end{tabular}

Table 2. Age and sex distribution of the students in different types of school.

\begin{tabular}{|c|c|c|c|c|c|}
\hline \multirow{2}{*}{ Types of school } & \multirow{2}{*}{ Sex } & \multicolumn{3}{|c|}{ Age group of patients in years } & \multirow{2}{*}{ Total } \\
\cline { 3 - 6 } & & $1-5$ & $6-10$ & $11-15$ & \\
\hline \multirow{3}{*}{ Government } & Male & 1 & 15 & 10 & 26 \\
\cline { 2 - 6 } & Female & 3 & 12 & 11 & 26 \\
\cline { 2 - 6 } & Total & 4 & 27 & 21 & 52 \\
\hline \multirow{7}{*}{ Private } & Male & 4 & 17 & 23 & 44 \\
\cline { 2 - 6 } & Female & 4 & 9 & 19 & 32 \\
\cline { 2 - 6 } & Total & 8 & 26 & 42 & 76 \\
\hline
\end{tabular}

Out of 128 students with refractive error, $44.5 \%$ (57) students were wearing glasses. $45.1 \%$ of the students from school of rural areas were wearing glasses while $43.2 \%$ of the students from school of urban areas were wearing glasses. (Table 3) Similarly, $56.6 \%$ of the students studying in private schools were wearing glasses but only $26.9 \%$ of the government school students were wearing glasses. (Table 4)

Table 3. Spectacles wearing student in different location

\begin{tabular}{|c|c|c|c|}
\hline \multirow{2}{*}{ Location of students } & \multicolumn{2}{|c|}{ Present glasses } & \multirow{2}{*}{ Total } \\
\hline & Yes & No & \\
\hline Rural & $41(45.1 \%)$ & $50(54.9 \%)$ & $91(100 \%)$ \\
\hline Urban & $16(43.2 \%)$ & $21(56.8 \%)$ & $37(100 \%)$ \\
\hline Total & $57(44.5 \%)$ & $71(55.5 \%)$ & $128(100 \%)$ \\
\hline
\end{tabular}

Table 4. Spectacles wearing student in different types of schools

\begin{tabular}{|c|c|c|c|}
\hline \multirow{2}{*}{ Types of schools } & \multicolumn{2}{|c|}{ Present glasses } & \multirow{2}{*}{ Total } \\
\hline & Yes & No & \\
\hline & $14(26.9 \%)$ & $38(73.1 \%)$ & $52(100 \%)$ \\
\hline Government & $43(56.6 \%)$ & $33(43.4 \%)$ & $76(100 \%)$ \\
\hline Private & $57(44.5 \%)$ & $71(55.5 \%)$ & $128(100 \%)$ \\
\hline
\end{tabular}

As shown as figure 2, non-dalittarai was the commonest ethnic group who participated in this study (27\%). Upper caste group and the janajati were in the second position ( $20 \%$ in each cast)

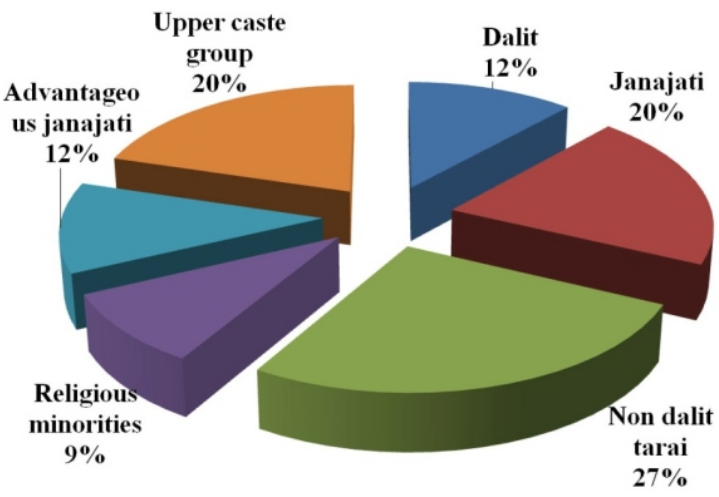

Figure 2. Distribution of the caste in participated students 
Table 5. Distribution of different ethnic group in different type of school.

\begin{tabular}{|c|c|c|c|}
\hline \multirow{2}{*}{ Ethnic group } & \multicolumn{2}{|c|}{ Type of school } & \multirow{2}{*}{$\begin{array}{c}\text { Total } \\
\text { (Percentage) }\end{array}$} \\
\cline { 2 - 3 } & Government & Private & $15(100 \%)$ \\
\hline Dalit & $12(80 \%)$ & $3(20 \%)$ & $26(100 \%)$ \\
\hline Janajati & $8(30.8 \%)$ & $18(69.2 \%)$ & 26 \\
\hline Non dalittarai & $20(58.8 \%)$ & $14(41.2 \%)$ & $34(100 \%)$ \\
\hline Religious minorities & $6(50 \%)$ & $6(50 \%)$ & $12(100 \%)$ \\
\hline Advantageous janajati & $2(13.3)$ & $13(76.7 \%)$ & $15(100 \%)$ \\
\hline Upper caste group & $4(15.4 \%)$ & $22(84.6 \%)$ & $26(100 \%)$ \\
\hline Total & $52(40.6 \%)$ & $76(59.4 \%)$ & $128(100 \%)$ \\
\hline
\end{tabular}

Twenty students were with unilateral ametropia. Astigmatism was found as the commonest type of refractive error [121 $(47.3 \%)$ of the total eyes]. Compound myopic astigmatism was most frequently found among astigmatism. In age group 0-5 years, $70.8 \%$ (17) eyes were astigmatism. Similarly, in age group 6-10 years astigmatism was found in 43.3\% (46) eyes and in age group 11-15 years, astigmatism was found in $46.0 \%$ (58) eyes. In total, hypermetropia was found in least number of patients $7.8 \%(20)$ of the total eyes. (Table 6 )

Table 6. Distribution of different sub-types of refractive error in students.

\begin{tabular}{|c|c|c|c|}
\hline Type of refractive error & Sub-type of refractive error & Number of eyes & Percentage \\
\hline Emetropia & Emmetropia & 20 & 7.8 \\
\hline \multirow{3}{*}{ Hypermetropia } & Low hyperopia & 7 & 2.7 \\
\hline & Medium hyperopia & 10 & 3.9 \\
\hline & High hyperopia & 32 & 12.5 \\
\hline \multirow{3}{*}{ Myopia } & Low myopia & 27 & 10.5 \\
\hline & Medium myopia & 12 & 4.7 \\
\hline & High myopia & 27 & 10.6 \\
\hline \multirow{6}{*}{ Astigmatism } & Simple hypermetropic astigmatism & 3 & 1.1 \\
\hline & Simple myopic astigmatism & 30 & 11.7 \\
\hline & $\begin{array}{c}\text { Compound hypermetropic } \\
\text { astigmatism }\end{array}$ & 13 & 5.0 \\
\hline & Compound myopic astigmatism & 58 & 22.7 \\
\hline & Mixed astigmatism & 17 & 6.6 \\
\hline & Total & 256 & 100 \\
\hline
\end{tabular}

Table 7. Types of refractive error of 256 eyes of 128 students in different age group

\begin{tabular}{|c|c|c|c|c|}
\hline \multirow{2}{*}{ Type of error } & \multicolumn{3}{|c|}{ Age group of the students (in years) } & \multirow{2}{*}{ Total } \\
\cline { 2 - 4 } & $1-5$ & $6-10$ & $11-15$ & \\
\hline \multirow{2}{*}{ Emmetropia } & $1(4.2 \%)$ & $13(12.3 \%)$ & $6(4.8 \%)$ & $20(7.8 \%)$ \\
\hline Hypermetropia & $6(25.0 \%)$ & $25(23.6 \%)$ & $18(14.3 \%)$ & $49(19.1 \%)$ \\
\hline Myopia & $0(0.0 \%)$ & $22(20.7)$ & $44(34.9 \%)$ & $66(25.8 \%)$ \\
\hline Astigmatism & $17(70.8 \%)$ & $46(43.4 \%)$ & $58(46.0 \%)$ & $121(47.3 \%)$ \\
\hline & $24(100.0 \%)$ & $106(100.0 \%)$ & $126(100.0 \%)$ & $256(100.0 \%)$ \\
\hline Total & \multicolumn{2}{|c|}{} & &
\end{tabular}

As shown in table 8, astigmatism was found in highest number of eyes in the entire ethnic groups.

Table 8. Distribution of refractive error in different ethnic group

\begin{tabular}{|c|c|c|c|c|c|c|c|}
\hline $\begin{array}{c}\text { Type of refractive } \\
\text { error }\end{array}$ & Dalit & Janajati & Non dalittarai & $\begin{array}{c}\text { Religious } \\
\text { minorities }\end{array}$ & $\begin{array}{c}\text { Advantageous } \\
\text { janajati }\end{array}$ & $\begin{array}{c}\text { Upper caste } \\
\text { group }\end{array}$ & Total \\
\hline Emmetropia & 3 & 4 & 7 & 0 & 4 & 2 & 20 \\
\hline Hypermetropia & 2 & 7 & 14 & 9 & 4 & 13 & 49 \\
\hline Myopia & 6 & 12 & 14 & 8 & 9 & 17 & 66 \\
\hline Astigmatism & 19 & 29 & 33 & 7 & 13 & 20 & 121 \\
\hline Total & 30 & 52 & 68 & 24 & 30 & 52 & 256 \\
\hline
\end{tabular}

Table 9. Best Corrected visual acuity in the best eye among 128 students

\begin{tabular}{|c|c|c|c|}
\hline \multicolumn{2}{|c|}{ Visual Impairment categories } & Frequency & Percent \\
\hline & $6 / 6-6 / 18$ & 110 & 85.9 \\
\hline$<6 / 18-6 / 60$ & 16 & 12.5 \\
\hline & $<6 / 60-3 / 60$ & 2 & 1.6 \\
\hline & Total & 128 & 100.0 \\
\hline
\end{tabular}

\section{DISCUSSION}

Primary school education is the most crucial educational years since children acquire the most learning during this particular period. Thus, good visual acuity in children is important to ensure optimum growth of their educational potentials. Subjects selected for this study represented both urban and rural areas, a near-equal gender distribution, and all subjects were from different ethnic groups.

The prevalence of refractive error was $2.36 \%$ in this study. In children, the prevalence of refractive errors varies widely. Less than $1 \%$ prevalence of refractive errors was reported in primary school children in rural Tanzania, ${ }^{7} 8.1 \%$ in Kathmandu, ${ }^{2} 8.6 \%$ in Jhapadistrict, ${ }^{15} 14.8 \%$ in Malaysia, ${ }^{8}$ $36.7 \%$ in Hong Kong, ${ }^{9}$ and more than $50 \%$ in Singapore. ${ }^{10}$ The wide variations of reported prevalence of refractive error could be attributed to several factors, including the targeted study population (population-based or school-based), methods of measurement (cycloplegia or non-cycloplegia), ethnicity and definition of terms such as the degrees of 
myopia, hyperopia and astigmatism., which compares favourably to the Gombak Study where the prevalence of uncorrected visual impairment was $17.1 \%$, reduced to less than $1.5 \%$ with best correction. ${ }^{8}$

Uncorrected visual acuity was $6 / 6$ to $6 / 18$ in 183 eyes but this was increased to 205 eyes after best correction. This shows that many patients improved their vision with proper refractive correction.

In our study more than two thirds of the participants were from schools located in rural area. The proportion of glass wearing students was similar in rural and urban areas. But, more students from private school were wearing glasses than those in government schools. It may be due to the fact that financially stronger people prefer the private schools and government school is the only option for poor people.

Non dalittarai/ madhesi caste was the most common ethnic group of the students with refractive error. Non dalittarai students were $27 \%$ followed by janajati and upper caste group each were $20 \%$. This shows that refractive error varies with different ethnic group. Saw et al, ${ }^{16} 2006$ also found out that refractive error varies with ethnicity. This study revealed that only few dalit students $(12 \%)$ were from private school but most of the upper caste group, advantageous janajati and janajati students were from private schools.

In this study, astigmatism was found as the most common type of refractive error comprising $47 \%$ of the children. As amblyopia is common in the children with astigmatism (Xiao et al, 2011) $)^{17}$, school children of this part of Nepal are highly vulnerable to the development of amblyopia. Among astigmatism, compound myopic astigmatism is the most common in all age groups. But in a study ${ }^{17}$ done in Chinese children by Xiao et al, 2011, compound hyperopic astigmatism was the most common type of astigmatism.

The prevalence of refractive error and uncorrected refractive error would provide a useful and informative figure for further planning of the national health programme. Many factors would need to be considered when deciding whether to introduce eye-screening programmes in primary schools. These factors include the prevalence of myopia, the impact of poor eyesight in children on their studies, human and financial resources needed for screening and referral, as well as availability and compliance of any treatment offered.

\section{CONCLUSION}

In the present study, it was observed that

- $71.1 \%$ of the students with refractive error were from schools located in rural (of which $45 \%$ were girls).

- The children in the 11-15 year age group had higher numbers of refractive errors (49\%).

- Twenty students were with unilateral ametropia. Astigmatism was found as the commonest type of refractive errors $(47.3 \%)$

- Males had a higher (54\%) proportion of refractive errors than females

- More than half of the students studying in private schools were wearing glasses but only $26.9 \%$ of the government school students were wearing glasses.

- $14.1 \%$ children had visual impairment due to refractive error.

\section{ACKNOWLEDGEMENT}

We wish to acknowledge Mrs. Sudha Risal Sharma, former librarian, LEI, Mr Ramesh Giri, optometrist LEI, Ms Sonisha Neupane for their valuable advice and help.

\section{REFERENCES}

1. He M, Zeng J, Liu Y, Xu J, Pokharel GP, Ellwein LB. Refractive error and visual in urban children in Southern China. Invest Ophthalmol Vis Sci 2004;45:793-9.

2. Nepal BP, Koirala S, Adhikary S. Ocular morbidity in school children in Kathmandu. BrJOphthalmol 2002;87:531-4.

3. Maul E, Barroso S, Munoz SR, Sperduto RD, Ellwein LB. Refractive error study in children: results from La Florida, Chile. Am JOphthalmol 2000;129:445-54.

4. Naidoo KS, Raghunandan A, Mashige KP, Govender P, Holden $B A$, Pokharel GP, et al. Refractive error and visual impairment in African children in South Africa. Invest Ophthalmol Vis Sci 2003;44:3764-70

5. World Health Organisation. The role of optometry in vision 2020. Community Eye Health 2002; 15:33-6.

6. Saw SM, Nieto FJ, Katz J, Schein OD, Levy B, Chew SJ. Factors related to the progression of myopia in Singaporean children. Optom Vis Sci 2000;77:549-54.

7. Wedner SH, Ross DA, Balira R, Kaji L, Foster A. Prevalence of eye diseases in primary school children in a rural area of Tanzania. Br JOphthalmol 2000;84:1291-7.

8. Goh PP, Abqariyah Y, Pokharel GP, Ellwein LB. Refractive error and visual impairment in school-age children in Gombak District, Malaysia. Ophthalmology 2005;112:678-85. 
9. Fan DS, Lam DS, Lam RF, Lau JT, Chong KS, Cheung EY, et al. Prevalence, incidence and progression of myopia of school children in Hong Kong. Invest Ophthalmol Vis Sci 2004;45:1071-5.

10. Tong L, Saw SM, Lin Y, Chia KS, Koh D, Tan D. Incidence and progression of astigmatism in Singaporean children. Invest Ophthalmol Vis Sci 2004;45:3914-8.

11. Seet B, Wong TY, Tan DT, Saw SM, Balakrishnan V, Lee LK, et al. Myopia in Singapore: taking a public health approach. Br J Ophthalmol 2001;85:521-6.

12. Matsumura H, Hirai H. Prevalence of myopia and refractive changes in students from 3 to 17 years of age. SurvOphthalmol 1999;44Suppl 1:S109-15.

13. Lin LL, Shih YF, Tsai CB, Chen CJ, Lee LA, Hung PT, et al. Epidemiologic study of ocular refraction among school children in Taiwan in 1995. Optom Vis Sci 1999;76:275-81.
14. Hosaka A. Population studies myopia experience in Japan. ActaOphthalmolSuppl 1988; 185:37-40.

15. Pokharel GP, Negrel AD, Munoz SR, Ellwein LB. Refractive error study in children: results from Mechi Zone, Nepal. Am J Ophthalmol 2000;129:436-44.

16. Saw SM, Goh PP, Cheng A, Shankar A, Tan DT, Ellwein LB. Ethnicity-specific prevalences of refractive errors vary in Asian children in neighbouring Malaysia and Singapore. $\mathrm{Br} \mathrm{J}$ Ophthalmol.2006 Oct;90(10):1230-5

17. Xiao X, Liu WM, Zhao WX, Wang Y, Zhang YJ. [Prevalence of astigmatism in 2023 children with amblyopia]. Zhongguo Dang Dai ErKeZaZhi. 2011 Jun;13(6):462-5 